International Journal of Engineering \& Technology, $7(3.27)(2018) 189-191$
International Journal of Engineering \& Technology
Website: www.sciencepubco.com/index.php/IJET
Research paper

\title{
Design of Conformal Microstrip Patch Antenna for Vehicle Tracking
}

\author{
B. Ebenezer Abishek ${ }^{1 *}$, Z. Abdul Hashim ${ }^{2}$, Hari Sai Prasath ${ }^{3}$, C. Arul Stephen ${ }^{4}$, P.C. Kishore Kumar ${ }^{5}$ \\ ${ }^{1}$ Research Scholar, Vels University. \\ ${ }^{2}$ Student, Department of ECE, Vels University. \\ ${ }^{3}$ Student, Department of ECE, Vels University. \\ ${ }^{4}$ Assistant Professor, Vels University. \\ ${ }^{5}$ Assistant Professor, Vels University. \\ *Corresponding author E-mail:abishek.se@velsuniv.ac.in
}

\begin{abstract}
The road accidents have increased in the urban areas to the level which is alarming. The accidents cause loss of human life which can be avoided if the accident victim is rescued at the earliest and given the necessary treatment. This paper involves the designing of an antenna unit for the purpose of tracking the vehicles met with the accidents. The tracking unit placed in vehicles requires a low profile antenna to be placed on top of the roof of vehicle. The simulation study of this antenna is performed in Feko Suite and validated in CST.
\end{abstract}

Keywords: Vehicle tracking, vehicular antenna, microstrip patch antenna.

\section{Introduction}

The usage of wireless communication for personal application has increased rapidly all around the world. The quality of the service provided in earlier days was low when compare to the quality of service provided today. The infrastructure facilities all around world for terrestrial mobile communication has increased, thus a vast majority of areas get good coverage. But still certain remote areas are without coverage.

Satellite based wireless communication is a solution for the above mention problem. Mobile communications utilizes satellite has advantage of transmitting and receiving traffic through broadcast or multicast methods.

The merits using the mobile satellite communication was first implemented by Japan aerospace exploration agency. The developed S band satellite called Engineering test satellite VIII. They also launched this satellite to space to conduct orbital experiments to prove the various functions of mobile satellite communication. This technology expected faster, accurate and error free data from satellite for a traffic control in case of emergency. Further the usage of GPS, regulating vehicular communication and electronic toll collection are utilized rapidly. In this research an antenna unit capable of establishing a communication link with the satellite even when moving at high speeds is design. We assume the satellite is a geo stationary satellite. The intended system requires a compact antenna. To reduce the size of the antenna unit, novel patch array antenna is proposed. The antenna has beam tracking capabilities. The antenna unit will be installed on top of a moving vehicle.

\section{System Architecture}

The system architecture consists of four blocks. They are satellite, transmission channel, fixed ground station and mobile ground station. The most important transmission problem is due to obstruction of various objects which causes loss in the received satellite signals. The other problems include shadowing effect due to trees and fading effect due to surrounding infrastructures and tree. This effect can be reduced when directional antenna's are utilized because they reduce refection of signals. Both the fixed ground station and movable ground station comprises of antenna, up/down converters, diplexer, power amplifier, low noise amplifier, demodulator and modulator. The satellite's system is similar to fixed ground station and movable round station but does not comprise a modulator and demodulator. The satellite receives a signal and transmits a signal after changing its frequency and magnifies the week signals. The metrics used to evaluate the performance of the system architecture are G/T(Figure of Merit), EIRP(Effective Isotropically Radiated Power) and C/NO(Carrier Power to Noise Power Ratio). The G/T and EIRP evaluates the transmission and reception capabilities of satellite, fixed ground station and mobile ground station. The $\mathrm{C} / \mathrm{NO}$ evaluates the transmission channel. The system architecture for the proposed work is shown in figure below.

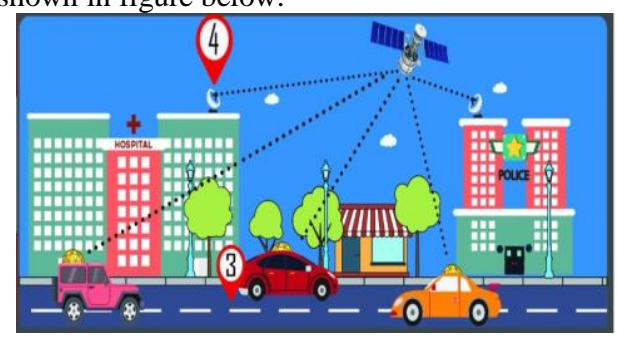

Fig. 1: System architecture

Apart from the system architecture shown in the above figure, various different system architectures are shown below which varies depending on the application of interest. The applications 
are limited to military, government agencies and also few private organizations for commercial purpose because communication through the satellite involves licensing issues.

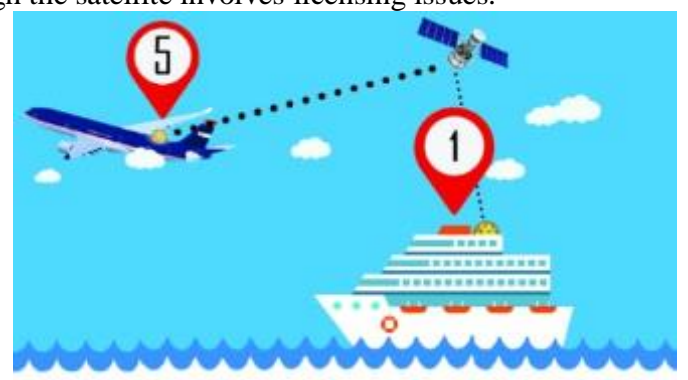

Fig. 2: Alternate system architecture

The Fig. 2. shown above illustrates an alternative system architecture which involves communication between vehicles moving at high speeds.

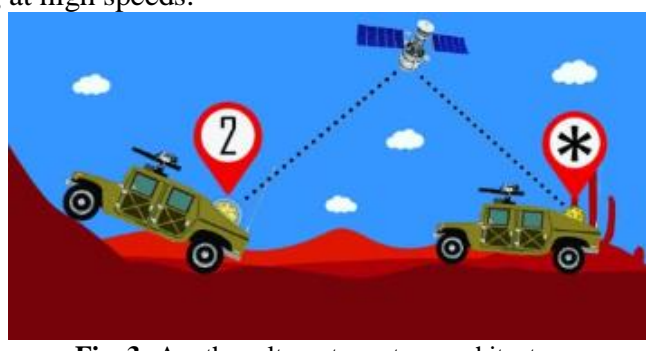

Fig. 3: Another alternate system architecture

The Fig. 3. shown above illustrates an another alternative system architecture in which the communication between army tanks and satellite is established and maintained even when the army tanks moves through rugged surfaces.

\section{Vehicular Antenna's}

The vehicular antenna's should have properties which satisfies electrical, mechanical and electromagnetic requirements. The required characteristics are described as follows

1. Mechanical Requirements: The antenna design should be light in weight and small in size to save space and for other structural reasons. Designing a compact antenna has a trade off which includes less gain, include beam width. Due to the reduced gain, the power supplied to the antenna needs to be increased but the battery of a vehicle has a constraint of supplying high power. The other requirement is wide band width. Designing an antenna with wide band width has a trade of interference with other systems and increased fading effect. The antenna when placed over a vehicle, it is considered as a mechanical structure which undergoes vibration effects when the vehicle moves at high speed, subjected to aerodynamics forces and sudden application of break causes vibration effects causing harmonics. These effects can be investigated using simulation tools by performing various analysis like modal analysis, harmonic analysis etc.

2. Electrical Requirements: The signal before transmission and after reception are purely electrical signals. According to the link budget given by Friss transmission formula, the important parameter for the signal to be received without being lost is input power. The only possible way to supply power to the vehicle mounted antenna is from the battery of the vehicle. The battery in the vehicle is charged from the fuel of vehicle. Therefore installation of the system increases the fuel consumption of vehicle which is undesired.

3. Electromagnetic Requirements: The International Telecommunication Union (ITU) regulates the satellite services like licensed frequency usage to different region of the world. The intended system requires a valid license from ITU to utilize the frequency band reserved for the purpose of mobile satellite communication. The antenna mounted on a vehicle for mobile satellite communication needs to circularly polarized to eliminate polarization tracking and other fading effects. According to the link budget given by Friss transmission formula, the important parameter for the signal to be received without being lost is the gain of transmitting and receiving antenna. Since the distance between the satellite and to fixed ground station or movable round station is large, the gain of the transmitting and receiving antenna should be high.

\section{Satellite Tracking}

The medium and high gain antenna's can perform satellite tracking contrary to omnidirectional antenna. The beam width of the antenna, speed of the vehicle reflects on the tracking capabilities of the antenna. The conventional accuracy required for satellite tracking is less than $1 \mathrm{~dB}$. Tracking functions of the satellite includes beam steering and tracking. The tracking system utilizes various structures to keep the antenna pointed to the satellite direction which is achieved using motors and drives. An alternative method to track the satellite is through electronic beam scanning. [30]

\section{Results \& Discussion}

The Fig. 4. shown below is the geometry of the designed antenna unit. It is a broadside array of four patch elements. The proposed design is constructed using RT Duroid 5880 material.

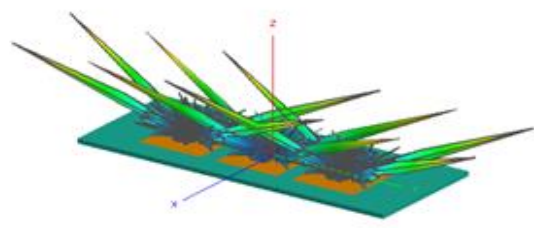

Fig. 4: Geometry of the designed antenna unit

The Fig. 5. shown below is the Cartesian gain plot of the proposed antenna unit. This result was obtained using Feko suite.

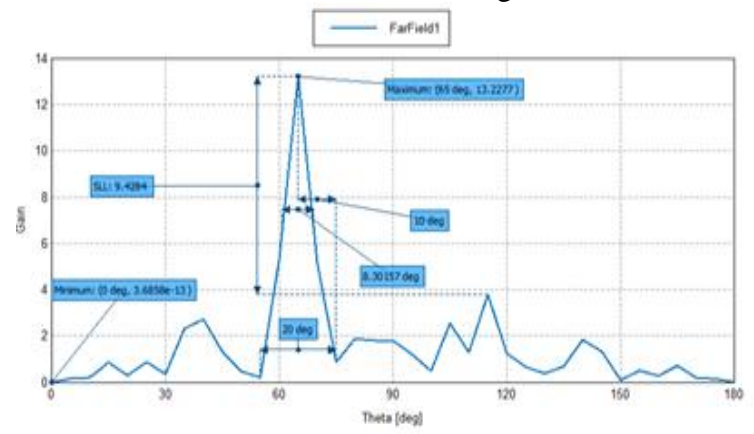

Fig. 5: Cartesian Gain plot of the proposed antenna unit

The Fig. 6. shown below is the polar gain plot of the proposed antenna unit. This result was obtained using Feko suite. 


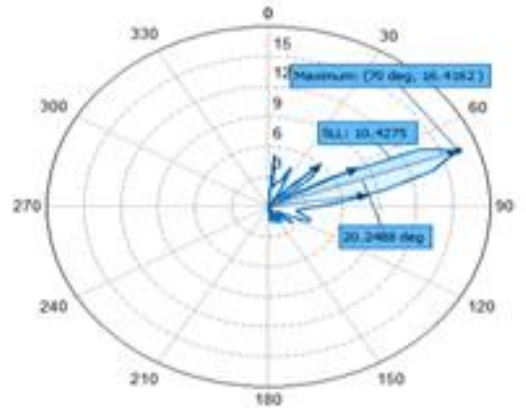

Fig. 6: Polar gain plot of the proposed antenna unit

The Fig. 7. shown below is the $S_{11}$ plot of the proposed antenna unit. This result was obtained using CST suite.

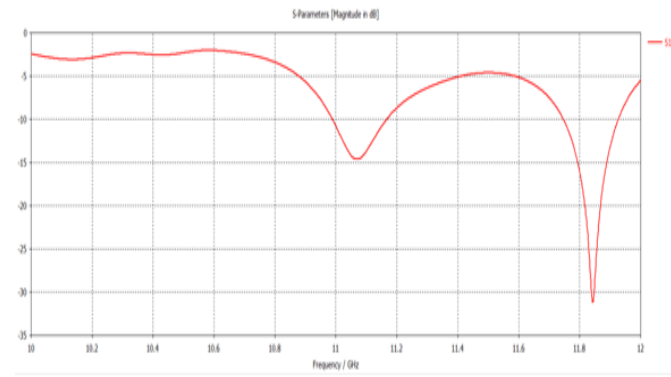

Fig. 7: S11 plot of the proposed antenna unit

The Fig. 8. shown below is the Cartesian gain plot of the proposed antenna unit. This result was obtained using CST suite.

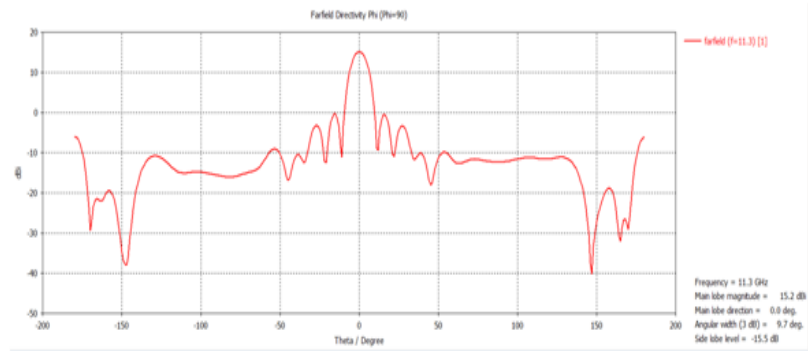

Fig. 8: Cartesian gain plot of the proposed antenna unit

The Fig. 9. shown below is the axial ratio plot of the proposed antenna unit. This result was obtained using CST suite.

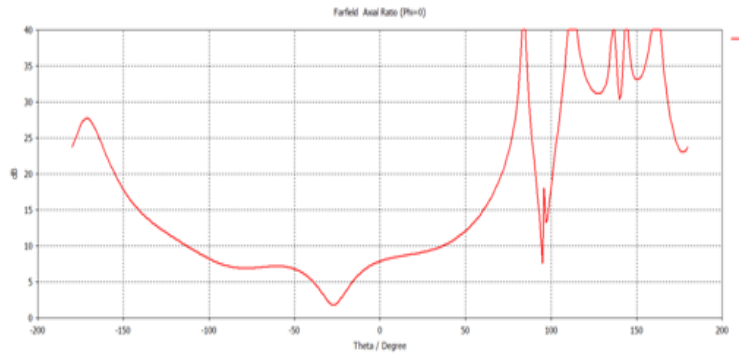

Fig. 9: Axial ratio plot of the proposed antenna unit

\section{Conclusion}

From the simulation study and its comparison with the requirements of vehicular antenna for vechile tracking,its infered that the proposed antenna is best suited for the purpose.

\section{References}

[1] Ebenezer Anishek B, Meena M \& Jerritta S, "FPGA Implementation of Reliable NOC", International Journal of Applied Engineering Research, Vol.10, No.17, (2015), pp.3183531843 .
[2] Abishek EB, Raja AVP, Kumar KPC, Stephen AC \& Raaza A, "Study and analysis of conformal antennas for vehicular communication applications", ARPN J. Eng. Appl. Sci., Vol.12, No.8, (2017), pp.2428-2433.

[3] Ebenezer Abishek B, Raaza A, Arul Stephen C, Rajenderan V \& Soundarya V, "Modal Analysis and Harmonic Analysis of a Conformal Antenna for Automobile Applications", International Journal of Control Theory and Applications, Vol.10, (2017), pp.17-23

[4] Zeng G, Li S \& Wei Z, "Research on conformal phased array antenna pattern synthesis", Proceedings of the International Conference on Information Technology and Software Engineering, (2013), pp.13-21.

[5] Schippers H, Verpoorte J, Jorna P, Hulzinga A, Meijerink A, Roeloffzen C, Heideman RG, Leinse A \& Wintels M, "Conformal phased array with beam forming for airborne satellite communication", International ITG Workshop on Smart Antennas, (2008), pp.343-350.

[6] Josefsson L \& Persson P, "Conformal array antenna theory and design", IEEE Press, John Wiley \& Sons, Hoboken, 2006.

[7] Biswas D, Priya BK, Nataraj B, Ramachandra V \& Dabade VN, "Design \& Development Of A Ku-Band Microstrip Array Antenna", 9th International Radar Symposium India, (2013).

[8] Chodavadiya VV \& Aggarwal SS, "Microstrip Patch Antenna Design for $\mathrm{Ku}$ Band Application", International Journal of Engineering Research \& Technology, Vol.3, No.4, (2014).

[9] Patel PD, Fundamentals of Phased Arrays, ASTRON, Netherlands, (2007).

[10] Hanumante V, Bhattacharjee P, Roy S, Chakraborty P \& Maity S, "Performance analysis of rectangular patch antenna for different substrate heights", International Journal of Innovative Research in Electrical, Electronics, Instrumentation and Control Engineering Vol.2, No.1,(2014), pp.515-518.

[11] Baggen L, Sanadgol B, Boettcher M, Holzwarth S \& Litschke O, "Designing integrated frontends for satcom applications", International Semiconductor Conference, Vol.1, (2012), pp.11-18.

[12] Josefsson L \& Persson P, "Conformal Array Antenna Theory And Design”, IEEE Antennas And Propagation Society, (2006).

[13] Vaccaro S, Tiezzi F, Llorens D, Rua MF \& de Oro CDG, "Ku-Band low profile antennas for mobile satcom", ASMS 4th Advanced Satellite Mobile Systems, (2008), pp.24-28.

[14] Balanis CA, Antenna Theory: Analysis and Design, 3rd ed, New York: Wiley, (2005).

[15] Riblet HJ, "Discussion of Dolph's paper", Proc. IRE, Vol.35 (1947), pp.489-492.

[16] Proakis JG \& Manolakis DG, Digital Signal Processing, 3rd Ed, New Jersey:Prentice Hall, (1996).

[17] DuHamel RH, "Optimum patterns for endfire arrays", Proc. IRE Vol.41, No.5, (1953), pp.652-659.

[18] Sinclair G \& Cairns FV, "Optimum patterns for arrays of nonisotropic sources", Trans. IRE, PGAP-1, (1952), pp.50-61.

[19] Holm S \& Elgetun B, "Optimization of the beampattern of 2D sparse arrays by weighting", Proc. IEEE Ultrasonics Symp., Cannes, France, (1995).

[20] Murino V, Trucco A \& Regazzoni CS, "Synthesis of unequally spaced arrays by simulated annealing", IEEE Trans. Signal Processing, Vol.44, (1996), pp.119-123.

[21] Widrow B, Mantey PE \& Griffiths LJ, "Adaptive antenna systems", Proc.IEEE, Vol.55, (1967), pp.2143-2159.

[22] Bevelacqua P \& Balanis CA, "Optimizing antenna array geometry forinterference suppression", IEEE Trans. Antennas Propag., Vol.53, (2007), pp.637-641.

[23] A.Surendar, Jayanthiladevi, A. "Fast Data vs. Big Data With IoT Streaming Analytics and the Future Applications." Handbook of Research on Cloud and Fog Computing Infrastructures for Data Science. IGI Global, 2018. 344-359.

[24] Li X \& Nie Z, "Effect of array orientation on performance of MIMO wireless channels", IEEE Antennas Propag. Letters, Vol.3, (2004), pp.368-372.

[25] Ulaby FT, Fundamentals of Applied Electromagnetics, New Jersey: Prentice Hall, (2001)

[26] Balanis CA, Advanced Engineering Electromagnetics, New York: Wiley, (1989).

[27] Stutzman WL \& Thiele GA, Antenna Theory and Design, 2nd Ed, New York:Wiley, (1998).

[28] Kraus JD \& Marhefka RJ, Antennas, 2nd Ed, New York: McGrawHill, (2001).

[29] Skolnik M, Introduction to Radar Systems, New York: McGrawHill, (2001) 
[30] Villalobos Antúnez, JV (2017). Karl R. Popper, Heráclito y la invención del logos. Un contexto para la Filosofía de las Ciencias Sociales. Opción Vol. 33, Núm. 84. 5-11 